\title{
Urgences
}

\section{Pouvoir ou prétendre...}

\section{Manuel Marienval}

Numéro 15, octobre 1986

Épigraphiques

URI : https://id.erudit.org/iderudit/025316ar

DOI : https://doi.org/10.7202/025316ar

Aller au sommaire du numéro

Éditeur(s)

Urgences

ISSN

0226-9554 (imprimé)

1927-3924 (numérique)

Découvrir la revue

Citer ce document

Marienval, M. (1986). Pouvoir ou prétendre... Urgences, (15), 51-51.

https://doi.org/10.7202/025316ar

Ce document est protégé par la loi sur le droit d'auteur. L'utilisation des services d'Érudit (y compris la reproduction) est assujettie à sa politique d'utilisation que vous pouvez consulter en ligne.

https://apropos.erudit.org/fr/usagers/politique-dutilisation/
Cet article est diffusé et préservé par Érudit.

Érudit est un consortium interuniversitaire sans but lucratif composé de l'Université de Montréal, l'Université Laval et l'Université du Québec à Montréal. Il a pour mission la promotion et la valorisation de la recherche. https://www.erudit.org/fr/ 


\section{Manuel Marienval}

J'étais raide et froid, j'étais un pont, je passais au-dessus d'un abîme.

Franz Kafka: La muraille de Chine

Pouvoir ou prétendre sans grande prétention ne pas se reprendre sur la manière de dire: ainsi, liquide pourrait le style tendre à ne pas trop s'étendre. À tort ou à raison, et par conséquent à travers, rien ne doit transparaître à cette intention qui comme un songe ne cherchera qu'à se contourner par des détours qui n'ont pas d'autre dessein que le jeu qui s'étire pour éviter de déclarer ou d'émettre certaines insanités qui dans le désordre des choses seraient mal à propos...

Si d'aventure, devenu pantoministre, bon gré mal gré pantin, j'allais môlheureusement m'immoler, me statuer dans le magma du mont Paradoxe. Si seulement j'osais, le temps de m'accomplir, de faire le pont. Non mais voyez-vous ça? Scrutez-moi cette cafetière pédantesque qui ne cesse d'éternuer.

N'y voyez pas d'entourloupette si je vais m'essaimant ou si je m'évapore à l'instant même. Ce n'est qu'un petit rien du tout qui lêvite légèrement ni plus ni moins. Au détour d'un hasard liquide et brumeux, ici et là, à tort ou à travers, quelques zouaves vocifèrent en procession de superlaxatifs à l'impuissance indécidément mal assise. Ces amères loques, comme un balbutiement de moimoiments intempestifs vitupérant d'un lupanar à l'autre paroxysmité.

Imaginez le Grand Guignol pontifiant une colonie de respirateurs asthmatiques, tous les fantoches, pigeons et dindons pindardisant qui tous en choeur bébégayent. Voyez donc l'icelui qui marine bredouille dans sa culture de libibidonnage et dites-moi qui se turlupine du chapeau tant et plus.

Panurge a les nerfs en pelote à défaut de ne jamais avoir jeté cette encre rouge qui lui salit les mains... En attendant que ça se passe, il éponge le gras de ses mots qui bavent, rigolent et crêvent dans d'insondables abysses filiformes, baromètres des supersifleurs aphasiques.

Et puis, ces supapertures, ces trucs et ces machins qui perdurent, comme d'inlassables cloportes en farandole, clopin-clopant sur le pont soupirant, convoient des vies d'anges avortées d'un rêve évidé à l'autre avide même... 